\title{
Relationship Between Intraprostatic Tracer Deposits and Sentinel Lymph Node Mapping in Prostate Cancer Patients
}

\author{
Tessa Buckle ${ }^{1,2}$, Oscar R. Brouwer ${ }^{1}$, Renato A. Valdés Olmos ${ }^{1}$, Henk G. van der Poel ${ }^{3}$, and Fijs W.B. van Leeuwen ${ }^{1,2}$ \\ ${ }^{1}$ Department of Nuclear Medicine, Netherlands Cancer Institute, Amsterdam, The Netherlands; ${ }^{2}$ Interventional Molecular Imaging \\ Section, Department of Radiology, Leiden University Medical Center, Leiden, The Netherlands; and ${ }^{3}$ Department of Urology, \\ Netherlands Cancer Institute, Amsterdam, The Netherlands
}

Intraprostatic injection of the hybrid tracer indocyanine green (ICG) ${ }^{99 m}$ Tc-nanocolloid enables both preoperative sentinel node $(\mathrm{SN})$ identification and intraoperative visualization of the $\mathrm{SN}$. Relating the fluorescence deposits in embedded prostate tissue specimens to the preoperatively detected SNs also provides the opportunity to study the influence of their placement on lymphatic drainage pattern. Methods: Nineteen patients with prostate carcinoma scheduled for robot-assisted laparoscopic prostatectomy and lymph node (LN) dissection were included. ICG_99mTc-nanocolloid was injected intraprostatically, guided by ultrasound. SN biopsy was performed using a combination of radioguidance and fluorescence guidance. Tracer distribution was visualized in paraffin-embedded prostate samples using ex vivo fluorescence imaging. This distribution was correlated to the number and location of the SNs identified on preoperative lymphoscintigraphy and SPECT/CT. Results: ICG-99mTc-nanocolloid helped guide surgical excision of the SNs. Ex vivo fluorescence imaging revealed a large variation in the locations of intraprostatic tracer deposits among patients. Tracer deposits in the peripheral zone correlated with a higher number of visualized LNs than deposits in the central zone (on average, 4.7 vs. 2.4 LNs per patient). Furthermore, tracer deposits in the mid gland correlated with a higher number of visualized LNs than deposits near the base or apex of the prostate (on average, 6 vs. 3.5 LNs per patient). Conclusion: The hybrid nature of the tracer not only enables surgical guidance but also provides an opportunity to study the correlation between the location of tracer deposits within the prostate and the number and location of preoperatively visualized SNs. These data suggest that the location at which a tracer deposit is placed influences the lymphatic drainage pattern.

Key Words: prostate; sentinel node; hybrid; surgical guidance; fluorescence

J Nucl Med 2012; 53:1026-1033

DOI: 10.2967/jnumed.111.098517

\footnotetext{
Received Sep. 20, 2011; revision accepted Feb. 6, 2012.

For correspondence or reprints contact: Fijs W.B. van Leeuwen, Leiden University Medical Center, Department of Radiology, Interventional Molecular Imaging Section, Albinusdreef 2, P.O. Box 9600 (section C2-S) 2300 RC, Leiden, The Netherlands.

E-mail: f.w.b.van leeuwen@lumc.nl

Published online May 29, 2012.

COPYRIGHT @ 2012 by the Society of Nuclear Medicine, Inc.
}

$\mathbf{L}$ in the cascade of metastatic prostate cancer spread. Unfortunately, diagnostic imaging modalities such as CT, MRI, and ${ }^{18}$ F-FDG PET lack sensitivity for identification of such metastases $(1,2)$. Currently, laparoscopic sentinel node (SN) biopsy followed by histopathologic examination of the excised tissue can be used to assess nodal status in prostate cancer patients $(3,4)$.

The concept of SN biopsy has been studied extensively in breast cancer and melanoma (5-7). For prostate cancer, the principle of $\mathrm{SN}$ detection is based on the assumption that accurate SN identification is possible after intraprostatic injection of a radioactive tracer guided by ultrasound $(8,9)$. As most of adenocarcinomas arise in the peripheral zone of the prostate $(10,11)$, placement of tracer deposits into this zone is considered favorable for the detection of tumor-draining SNs. It is currently not clear whether the lymphatic drainage pattern is dependent on the location of the tracer deposits. Accurate placement of the intraprostatic tracer deposits may increase the reliability of the entire SN procedure. However, monitoring of injection accuracy using the radioactive signature of the injected tracer is difficult.

The extent of $\mathrm{LN}$ dissection in prostate cancer is a topic of debate $(8,12)$. Whereas some have argued that sole excision of the $\mathrm{SN}$ is a sensitive method to detect metastases and micrometastases, others favor extensive nodal dissection. Since unexpected locations of SNs outside the field of an extended pelvic lymphadenectomy are not rare, it is crucial that SNs are accurately identified preoperatively, as well as intraoperatively (9).

Because radioguided intraoperative localization of SNs based on the acoustic signal generated by a $\gamma$-probe has its drawbacks, we previously expanded surgical guidance with fluorescence imaging. To achieve this, we developed a hybrid radiocolloid that can be visualized with a $\gamma$-camera, SPECT/CT imaging, and near-infrared fluorescence imaging $(13,14)$. This hybrid radiocolloid enabled us to link preoperative SN identification to intraoperative visualization of the SNs in patients with prostate carcinoma (15). Ex vivo assessment of embedded tissue specimens revealed that the fluorescence signal could still be detected long after 
the radioactivity had decayed (15). Reasoning that the fluorescent beacon could also be used to analyze intraprostatic tracer distribution in retrospect, we have analyzed the presence of fluorescence signal in prostate specimens. The location of the tracer deposits in the prostate was correlated to the number and location of SNs identified by lymphoscintigraphy and SPECT/CT.

\section{MATERIALS AND METHODS}

\section{Patients}

The protocol (N09IGF, NL28143.031.09) was approved by the local ethics committee of The Netherlands Cancer InstituteAntoni van Leeuwenhoek Hospital. Between June 2010 and February 2011, 19 patients with prostate carcinoma of intermediate prognosis scheduled for robot-assisted laparoscopic prostatectomy and retroperitoneal $\mathrm{LN}$ dissection were included after giving written informed consent. Inclusion criteria and complete patient characteristics are listed in the online supplemental data (available at http://jnm.snmjournals.org). In the current study, we performed ex vivo analyses on the prostate specimens obtained during the surgical intervention described below.

\section{Tracer Preparation}

Tracer was prepared as previously described (15). ${ }^{99 \mathrm{~m}} \mathrm{Tc}-$ nanocolloid was prepared by adding $1 \mathrm{~mL}$ of pertechnetate $(\sim 700$ $\mathrm{MBq}$ ) in saline to a vial containing albumin nanocolloid (NanoColl; GE Healthcare). ICG-Pulsion (Pulsion Medical Systems) was prepared by dissolving $25 \mathrm{mg}$ of solid indocyanine green (ICG) in $5 \mathrm{~mL}$ of demineralized water. The ICG- ${ }^{99 \mathrm{~m}} \mathrm{Tc}-$ nanocolloid solution was prepared by adding $0.050 \mathrm{~mL}(0.250 \mathrm{mg}$ ICG) of the ICGPulsion solution to $1 \mathrm{~mL}$ of ${ }^{99 m} \mathrm{Tc}$-nanocolloid solution ( $\mathrm{pH}$ 6-7). ICG-99mTc-nanocolloid was formed via noncovalent interactions between ICG and albumin molecules (13-15). All procedures were performed under Kern Energie Wet (Nuclear Energy Law) using Dutch guidelines for good manufacturing practices and with the approval of the local pharmacist.

\section{Tracer Administration and Preoperative Imaging}

Tracer was administered approximately $3 \mathrm{~h}$ before surgery (Supplemental Fig. 1). Transrectal positioning of the needle into the prostate was guided by ultrasound (Hitachi). Injections were performed by 3 different urologists. Subsequently, both lobes of the prostate were injected with 2 tracer deposits of $0.1 \mathrm{~mL}$ each (total volume, $0.4 \mathrm{~mL}$; average dose, $280 \mathrm{MBq}$ ). The needle and tubing were flushed with approximately $0.7 \mathrm{~mL}$ of saline after each tracer deposit. To assess whether each tracer deposit was adequately delivered, we monitored intraprostatic tracer retention using a portable $\gamma$-camera equipped with a pinhole collimator (Sentinella; Oncovision). Planar lymphoscintigraphy (anterior and lateral 5-min images) was performed in the nuclear medicine department at $15 \mathrm{~min}$ and $2 \mathrm{~h}$ after injection using a hybrid dualhead camera (Symbia T; Siemens). The first node in each nodal basin appearing on early planar imaging was considered to be the SN (SN1), whereas LNs appearing later in the same basin were considered higher-echelon nodes. For anatomic localization of the nodes, SPECT/CT was performed directly after planar imaging at $2 \mathrm{~h}$ after injection using the same camera system. If SPECT/CT revealed additional hot spots in caudal areas or on a side without previous drainage, these hot spots were also considered to be SNs. The amount of radioactivity in the SNs was determined by mea- suring the counts $/ \mathrm{cm}^{2}$ per LN using OsiriX software (Pixmeo). The total activity on the left and right sides of the body was determined by calculating the sum of the measured counts in all visualized LNs. Using these counting rates, the total percentage of radioactivity per patient and the mean percentage of radioactivity on each side were calculated. To determine the mean percentage of radioactivity in $\mathrm{SN} 1$, only counting rates in that $\mathrm{SN}$ were used.

\section{Surgical Procedure}

SNs were intraoperatively localized and excised after prostatectomy using a laparoscopic $\gamma$-probe (Europrobe; EuroMedical Instruments) and a fluorescence laparoscope (D-light system; Karl Storz Endoscopes). A retroperitoneal LN dissection was performed after SN excision in all patients. When no SNs were identified preoperatively, a $\mathrm{LN}$ dissection was performed comprising the internal and external iliac nodes and the obturator nodes (15).

\section{Ex Vivo Specimen Analysis}

Fluorescence imaging of paraffin-embedded prostate tissue was used to visualize the location of the tracer injections and its distribution throughout the prostate. For each patient, 2-6 sections were analyzed. An overview of the tracer deposits throughout the prostate was created by combining the sections of each patient. Figure 1 illustrates the different zones and the orientation of the prostate; the $x$-axis shows the difference between the left and right sides of the prostate, the $y$-axis follows the path from the bottom (peripheral zone) to the top (central zone), and the $z$-axis follows the base to the apex of the prostate. No discrimination was made between the transition and central zones; both are specified as the central zone. Fluorescence signal intensities were measured using an IVIS 200 camera (Xenogen Corp.). Images were acquired with standard ICG filter settings (excitation, 710-760 nm; emission, $810-875 \mathrm{~nm}$ ). Measured intensities (photons $/ \mathrm{s} / \mathrm{cm}^{2} / \mathrm{sr}$ ) were quantified using Living Imaging Acquisition and Analysis software (Xenogen Corp.). For analysis, the prostate was divided into 4 quadrants (Q1-Q4, Fig. 1B), with Q1 and Q3 representing the left side of the prostate and Q2 and Q4 representing the right side. Q1 and Q2 were deemed to include the largest part of the central zone of the prostate, whereas Q3 and Q4 were deemed to mostly rep-

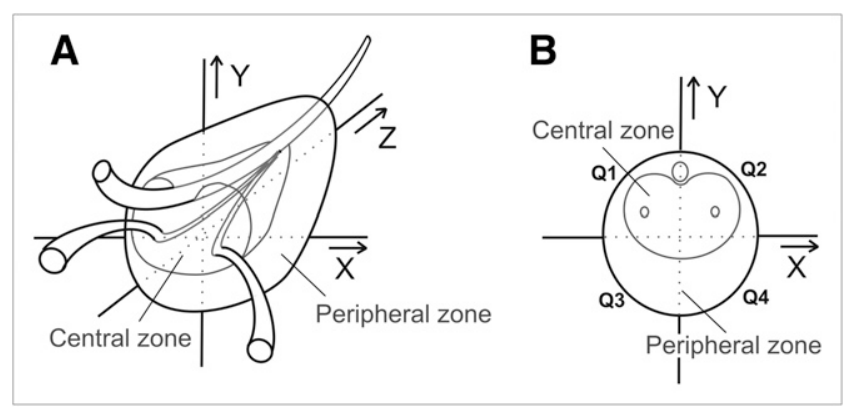

FIGURE 1. Schematic representation of prostate. (A) Within prostate, discrimination can be made between peripheral and central zones because of differences in tissue morphology. Base of prostate is wider than apex and is next to bladder. (B) For quantification purposes, embedded sections of prostate samples were divided into 4 quadrants (Q1-Q4). Q1 and Q2 represent central zone, and Q3 and Q4 represent peripheral zone. 
resent the peripheral zone. Per section, distribution of the fluorescence signal was evaluated, and the mean percentage of fluorescence in each quadrant was calculated.

\section{RESULTS}

We previously reported the use of ICG- ${ }^{99 \mathrm{~m}} \mathrm{Tc}$-nanocolloid for combined preoperative detection and image-guided dissection of SNs in 11 patients with prostate carcinoma using radioguidance and fluorescence guidance (15). In the 19 patients reported here ( 8 additional patients included), we explored the possibility of assessing placement of the tracer deposit ex vivo with fluorescence imaging and the relationship between these data and the scintigraphic findings. The efficacy of the hybrid guidance procedure in this enlarged patient population remained similar to the previous report (Supplemental Fig. 2).
Pathologic analysis of the embedded prostate samples showed that, in all prostate samples, tumor tissue was present mainly in Q3 and Q4 (84\%), corresponding to the bottom half and peripheral zone of the prostate (Fig. 1). Supplemental Table 2 shows the location of tumor in each patient.

\section{Ex Vivo Fluorescence Imaging of the Tracer Deposits}

Within the paraffin-embedded sections of the prostate, fluorescence could still be detected more than 2 months after prostatectomy and embedding of the tissue. Overlay pictures wherein the fluorescence image was superimposed on a photograph of that specific section of the prostate were used to determine the location of the tracer deposits. Figure 2 illustrates the variations that were found. Figure $2 \mathrm{~A}$ depicts the fluorescence signal in the different sections of the prostate and the corresponding lymphoscintigraphy image in 2

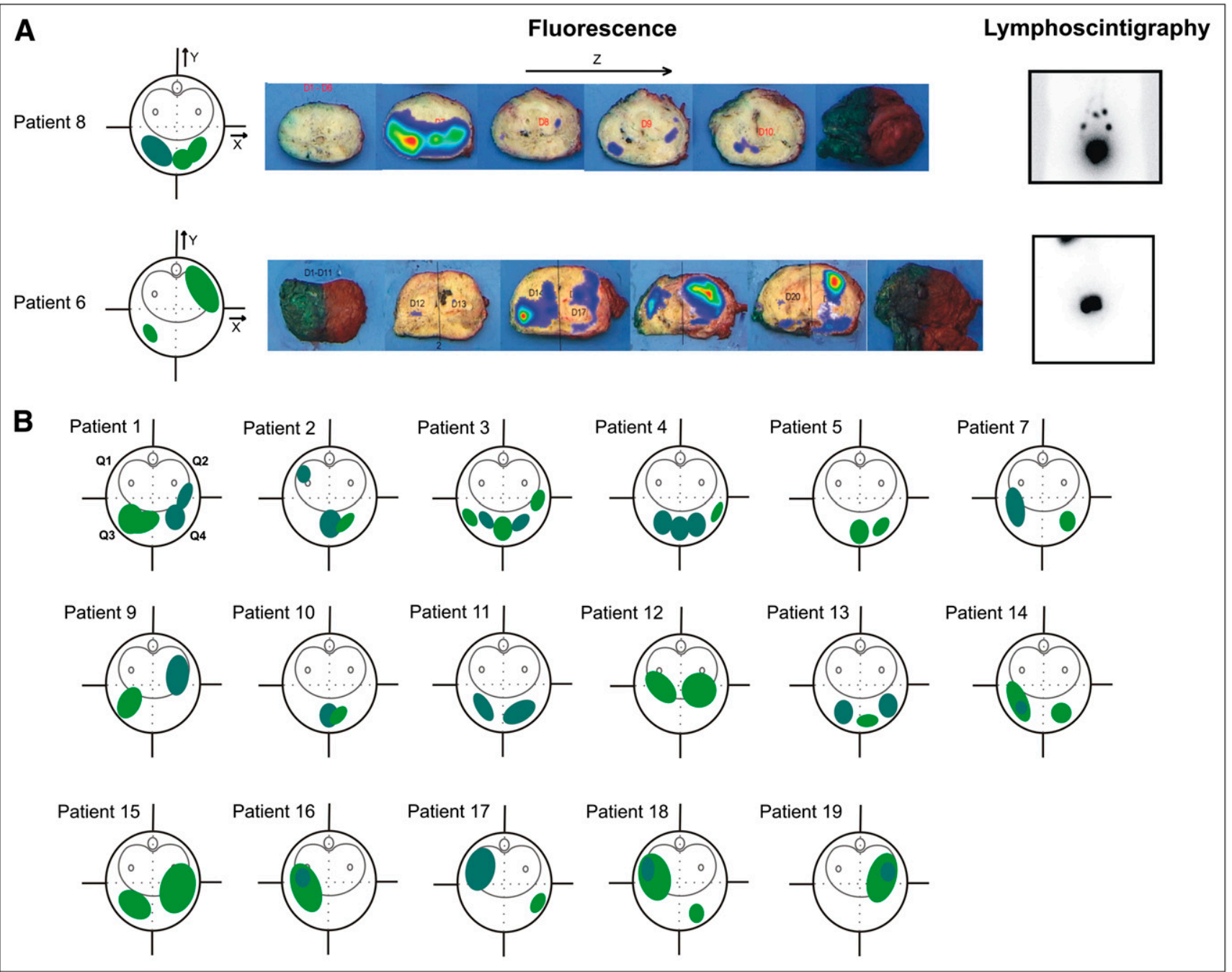

FIGURE 2. Variations in tracer distribution throughout prostate. (A) Patient for whom injected tracer was evenly distributed over left and right sides of peripheral zone (patient 8), and patient for whom tracer was mostly on right side of central zone with single deposit on left side of peripheral zone (patient 6). These images also illustrate variation in z-direction. (B) Overview of tracer deposits per prostate sample. Prostate is blue, and fluorescence deposits are green (light green for deposits with comparable or low intensity; dark green for deposits with high intensity). 
representative patients; in patient 8 the tracer was injected into the peripheral zone, and in patient 6 the tracer was injected into the central zone. The locations of tracer deposits for each patient are graphically represented in Figure 2B, where fluorescent deposits are depicted in green. Clearly, deposits vary in size, intensity (light green depicts deposits with identical or low intensities, and dark green depicts deposits with high fluorescent intensity), and location.

To provide a more quantitative readout, the mean percentage of fluorescence in every quadrant of the prostate (Q1-Q4; Fig. 1) per patient is shown in Table 1. In most patients, the sum of Q3 and Q4 (mostly representing the peripheral zone) was higher than the sum of Q1 and Q2 (including the largest part of the central zone). In $68 \%$ of patients, a clear difference in signal presence was observed between the left and right sides. In $53 \%$ of patients, the tracer was injected in the peripheral zone of the prostate; in $31 \%$, in the peripheral and central zone; and in $16 \%$, only in the central zone (Fig. 1, y-axis).

Evaluation of distribution from the base to the apex of the prostate (Table 1; Fig. 1, z-axis) revealed that in $47 \%$ of patients the fluorescence signal was evenly distributed over all sections. In $21 \%$ of patients, a larger deposit near the base or the apex was detected. In $16 \%$ of patients, the fluorescence signal was present only near the base and apex, whereas in another $16 \%$, the fluorescence signal was present only in the mid gland of the prostate.

\section{Radioactivity-Based Evaluation of Lymphatic Drainage}

Portable $\gamma$-camera images were used to confirm adequate tracer delivery in the prostate (Supplemental Data), whereas lymphoscintigraphy and subsequent SPECT/CT were used to visualize the SNs and second-echelon nodes.

TABLE 1

Fluorescence Distribution Observed Ex Vivo

\begin{tabular}{|c|c|c|c|c|c|c|}
\hline $\begin{array}{l}\text { Patient } \\
\text { no. }\end{array}$ & Q1 & Q2 & Q3 & Q4 & Injection site & $\begin{array}{c}\text { Tracer distribution throughout } \\
\text { prostate* }\end{array}$ \\
\hline 1 & $12 \pm 5$ & $16 \pm 5$ & $34 \pm 8$ & $37 \pm 15$ & $\begin{array}{l}\text { L peripheral zone, R peripheral } \\
\text { and central zone }\end{array}$ & $\begin{array}{l}\text { No FL in mid gland; deposits } \\
\text { near base and apex }\end{array}$ \\
\hline 2 & $19 \pm 3$ & $13 \pm 1$ & $40 \pm 9$ & $28 \pm 7$ & $\begin{array}{l}\text { Central in prostate, mostly } \\
\text { peripheral zone }\end{array}$ & $\begin{array}{l}\text { FL mostly in mid gland; hot } \\
\text { spot } L \text { central zone }\end{array}$ \\
\hline 3 & $12 \pm 4$ & $17 \pm 8$ & $36 \pm 6$ & $37 \pm 7$ & Central in prostate, peripheral zone & Evenly over all sections \\
\hline 4 & $11 \pm 2$ & $13 \pm 3$ & $35 \pm 13$ & $41 \pm 11$ & Central in prostate, peripheral zone & FL mostly in central section \\
\hline 5 & $13 \pm 3$ & $26 \pm 8$ & $23 \pm 6$ & $36 \pm 4$ & Central in prostate, peripheral zone & Evenly over all sections \\
\hline 6 & $15 \pm 4$ & $35 \pm 18$ & $23 \pm 6$ & $33 \pm 12$ & Mostly central zone & Evenly over all sections \\
\hline 7 & $16 \pm 8$ & $12 \pm 5$ & $52 \pm 16$ & $20 \pm 4$ & Mostly peripheral zone & $\begin{array}{l}\text { FL in all sections; largest } \\
\text { deposit near base }\end{array}$ \\
\hline 8 & $12 \pm 2$ & $12 \pm 5$ & $44 \pm 9$ & $32 \pm 7$ & Peripheral zone & FL mostly in mid gland \\
\hline 9 & $12 \pm 6$ & $21 \pm 13$ & $43 \pm 19$ & $27 \pm 14$ & $\begin{array}{l}\text { L peripheral zone, } \mathrm{R} \text { mostly } \\
\text { central zone }\end{array}$ & $\begin{array}{l}\text { FL in all sections; largest } \\
\text { deposit near apex }\end{array}$ \\
\hline 10 & $13 \pm 5$ & $15 \pm 5$ & $31 \pm 4$ & $41 \pm 7$ & Central in prostate, peripheral zone & Evenly over all sections \\
\hline 11 & $10 \pm 3$ & $9 \pm 2$ & $55 \pm 5$ & $26 \pm 4$ & Peripheral zone & $\begin{array}{l}\text { No FL in mid gland; deposits } \\
\text { near base and apex }\end{array}$ \\
\hline 12 & $14 \pm 4$ & $25 \pm 12$ & $24 \pm 4$ & $37 \pm 12$ & Peripheral zone and central zone & Evenly over all sections \\
\hline 13 & $12 \pm 4$ & $13 \pm 3$ & $44 \pm 14$ & $30 \pm 12$ & Peripheral zone & $\begin{array}{l}\text { No FL in mid gland; deposits } \\
\text { near base (L) and apex (R) }\end{array}$ \\
\hline 14 & $23 \pm 11$ & $19 \pm 9$ & $34 \pm 15$ & $24 \pm 10$ & Peripheral zone & $\begin{array}{l}\text { FL in all sections; largest } \\
\text { deposit near base }\end{array}$ \\
\hline 15 & $6 \pm 1$ & $24 \pm 11$ & $32 \pm 12$ & $37 \pm 11$ & Peripheral zone and R central zone & Evenly over all sections \\
\hline 16 & $28 \pm 13$ & $16 \pm 5$ & $40 \pm 13$ & $16 \pm 5$ & L central zone and peripheral zone & Evenly over all sections \\
\hline 17 & $43 \pm 13$ & $8 \pm 3$ & $41 \pm 12$ & $8 \pm 2$ & L central zone & Evenly over all sections \\
\hline 18 & $18 \pm 8$ & $10 \pm 5$ & $52 \pm 9$ & $20 \pm 7$ & L mostly central zone & Evenly over all sections \\
\hline 19 & $7 \pm 3$ & $40 \pm 12$ & $12 \pm 5$ & $48 \pm 11$ & R mostly central zone & $\begin{array}{l}\text { FL in all sections; largest } \\
\text { deposit near base }\end{array}$ \\
\hline
\end{tabular}

*Figure 2 shows schematic overview of signal distribution throughout prostate per patient.

$\mathrm{FL}=$ fluorescence.

In Q1-Q4, mean percentage of fluorescence per quadrant is shown. Injection site was determined by evaluation of fluorescence signal in different zones of prostate (central, Q1 and Q2; peripheral, Q3 and Q4). Distribution throughout prostate was determined by evaluating fluorescence in each section of prostate. 
Except for patient 6, in whom no SNs could be visualized, SNs were found predominantly in the region of the obturator nerve and internal and external iliac vessels. In patient 15 , the SN could be visualized with SPECT/CT only at $2 \mathrm{~h}$ after injection, whereas in all other patients a $\mathrm{SN}$ was visualized with lymphoscintigraphy at $15 \mathrm{~min}$ after injection. In 6 patients (32\%; patients $2,5,7,9,14$, and 17$)$, SNs situated farther along the obturator-internal/external iliac drainage route were identified.
As listed in Table 2, lymphatic drainage was not equally distributed over both sides of the patients. In 11 patients, more LNs were found on the left side $(61 \%)$, whereas in 3 patients, more LNs were found on the right side (17\%). In 4 patients, the same number of LNs was found on both sides (22\%). Besides the number of LNs visualized, the activity measured in SN1 on each side was also slightly different. Table 2 notes the side with the highest activity. In 12 patients, a higher signal was measured in SN1 on the left

TABLE 2

Radioactivity-Based Distribution in Preoperatively Defined SN

\begin{tabular}{|c|c|c|c|c|c|c|c|}
\hline \multirow[b]{2}{*}{$\begin{array}{c}\text { Patient } \\
\text { no. }\end{array}$} & \multirow[b]{2}{*}{ SNs on lymphoscintigraphy } & \multicolumn{3}{|c|}{ Left } & \multicolumn{3}{|c|}{ Right } \\
\hline & & $\begin{array}{l}\text { Number } \\
\text { of LNs }\end{array}$ & $\begin{array}{c}\text { SN1 } \\
\text { (counts) }\end{array}$ & $\begin{array}{c}\text { Total } \\
\text { (counts) }\end{array}$ & $\begin{array}{l}\text { Number } \\
\text { of LNs }\end{array}$ & $\begin{array}{c}\text { SN1 } \\
\text { (counts) }\end{array}$ & $\begin{array}{c}\text { Total } \\
\text { (counts) }\end{array}$ \\
\hline \multirow[t]{2}{*}{1} & L: 2 (ext., int.,) & $4^{*}$ & 1,971 & 3,943 & 1 & 1,573 & 1,573 \\
\hline & R: 1 (ext.) & & $\dagger$ & $\ddagger$ & & & \\
\hline \multirow[t]{2}{*}{2} & L: 2 (int., presacral) & $4^{*}$ & 1,808 & 4,714 & 1 & 1,705 & 1,705 \\
\hline & R: 1 (ext.) & & $\dagger$ & $\ddagger$ & & & \\
\hline \multirow[t]{2}{*}{3} & L: 3 (obt.) & $2^{*}$ & 1,973 & 2,928 & 1 & 799 & 799 \\
\hline & R: 1 (obt.) & & $\dagger$ & $\ddagger$ & & & \\
\hline \multirow[t]{2}{*}{4} & L: 3 (obt.) & $3^{*}$ & 553 & 1,435 & 1 & 1,051 & 1,051 \\
\hline & R: 1 (obt.) & & & $\ddagger$ & & $\dagger$ & \\
\hline \multirow[t]{2}{*}{5} & L: 1-2 (obt.) & 1 & 796 & 796 & 1 & 1,367 & 1,367 \\
\hline & R: 1 (comm. bif.) & & & & & $\dagger$ & $\ddagger$ \\
\hline \multirow[t]{2}{*}{6} & $\mathrm{~L}:-$ & - & - & - & - & - & - \\
\hline & $\mathrm{R}:-$ & & & & & & \\
\hline \multirow[t]{2}{*}{7} & L: 1 (ext.) & 1 & 2,292 & 2,292 & 1 & 1,505 & 1,505 \\
\hline & $\mathrm{R}: 1$ (comm.) & & $\dagger$ & $\ddagger$ & & & \\
\hline \multirow[t]{2}{*}{8} & L: 2 (obt., aorta bifurcation) & 3 & 4,087 & 10,008 & 2 & 2,998 & 4,022 \\
\hline & R: 1(obt.) & & $\dagger$ & $\ddagger$ & & & \\
\hline \multirow[t]{2}{*}{9} & L: 1 (obt.) & 5 & 2,396 & 6,507 & 5 & 1,772 & 5,622 \\
\hline & R: 2 (obt., paracaval) & & $\dagger$ & $\ddagger$ & & & \\
\hline \multirow[t]{2}{*}{10} & L: 2 (ext., int.,) & $4^{*}$ & 3,050 & 5,053 & 2 & 1,576 & 2,084 \\
\hline & R: 2 (ext., int.,) & & $\dagger$ & $\ddagger$ & & & \\
\hline \multirow[t]{2}{*}{11} & L: 1 (obt.) & $2^{*}$ & 639 & 1,134 & 1 & 1,784 & 1,784 \\
\hline & R: 1 (ext.) & & & & & $\dagger$ & $\ddagger$ \\
\hline \multirow[t]{2}{*}{12} & L: 2 (ext., int.,) & $4^{*}$ & 3,233 & 7,787 & 2 & 1,188 & 3,128 \\
\hline & R: 1 (ext.) & & $\dagger$ & $\ddagger$ & & & \\
\hline \multirow[t]{2}{*}{13} & L: 1 (obt.) & 1 & 585 & 585 & $2^{*}$ & 982 & 1,324 \\
\hline & R: 1 (obt.) & & & & & $\dagger$ & $\ddagger$ \\
\hline \multirow[t]{2}{*}{14} & L: 2 (obt., comm.) & $3^{*}$ & 1,851 & 3,967 & 1 & - & 632 \\
\hline & $\mathrm{R}:-$ & & $\dagger$ & $\ddagger$ & & & \\
\hline \multirow[t]{2}{*}{15} & $\mathrm{~L}:-$ & - & - & 371 & - & $-\S$ & 404 \\
\hline & R: 1 (obt.) & & & & & $\dagger$ & $\ddagger$ \\
\hline \multirow[t]{2}{*}{16} & L: 2 (obt., int., ext.) & 2 & 4,005 & 5,775 & 2 & 877 & 1,745 \\
\hline & R: 1 (obt.) & & $\dagger$ & $\ddagger$ & & & \\
\hline \multirow[t]{2}{*}{17} & L: 2 (int., comm.) & $2^{*}$ & 1,305 & 2,131 & - & - & 772 \\
\hline & $\mathrm{R}:-$ & & $\dagger$ & $\ddagger$ & & & \\
\hline \multirow[t]{2}{*}{18} & L: 1 (obt.) & $2^{*}$ & 691 & 1,120 & 1 & 454 & 454 \\
\hline & R: 1 (obt.) & & $\dagger$ & $\ddagger$ & & & \\
\hline \multirow[t]{2}{*}{19} & $\mathrm{~L}:-$ & - & - & 760 & $2^{*}$ & 1,227 & 2,093 \\
\hline & R: 1 (ext.) & & & & & $†$ & $\ddagger$ \\
\hline
\end{tabular}

*Highest number of visualized LNs (L or R).

${ }^{\dagger}$ Highest amount of counts in SN1 ( $L$ or $R$ ).

${ }^{\ddagger}$ Highest activity (total; L or R).

§SN visualized only on SPECT/CT.

ext. = external iliac; int. = internal iliac; obt. = obturator; comm. bif. = common iliac bifurcation; comm. = common iliac. 
side $(67 \%)$, whereas in 6 patients, a higher signal was measured in SN1 on the right side (33\%). This same trend was seen when the total activity per side was assessed; in 13 patients, the total activity was higher on the left side than on the right side $(72 \%)$.

\section{Relationship Between Tracer Deposit Location (Fluorescence-Based) and Lymphatic Drainage Pattern (Radioactivity-Based)}

To evaluate the relationship between the location of the tracer deposits and drainage to the LNs, the fluorescence signals were directly correlated with the measured activity in the visualized LNs. Patient 6 was excluded from the comparison because preoperative images of this patient showed no drainage.

Comparison of the fluorescence detected on the left and right sides of the prostate (Fig. 1, $x$-axis) with the radioactivity measured on each side of the body (Table 3 ) resulted in a positive trend in 10 patients $(56 \%)$. In these patients, the highest percentage of fluorescence was on the side with the highest counting rates. When the fluorescence and the radioactivity in SN1 were compared, this percentage increased to $67 \%$. This finding-and the fact that in patients for whom tracer was deposited mostly on one side of the prostate a larger number of LNs could be visualized on that side (Table 2)—suggests that lymphatic drainage may be influenced by the site of injection ( $x$-axis).

The influence of the injection site is underlined by the 8 patients for whom no positive correlation between deposit distribution and drainage pattern was found (Table 3). In 2 patients, the lack of a correlation could not be explained, whereas in the remaining 6 patients, a clear deposit in the central zone of the prostate (patients 1, 3, 7, and 12-14; Fig. 2 ; Table 1) was observed. The possible link between placement of deposits at different locations in the prostate (Fig. 1, $y$-axis) and the drainage pattern was further evaluated. The locations of fluorescent deposits in the prostate (Table 1) were correlated to the number of LNs detected on lymphoscintigraphy (Table 2). The presence of fluorescence in the central zone of all prostate sections resulted in visualization of a mean of 2.4 LNs per patient (patients 15-19). However, when the fluorescence was predominantly situated in the peripheral

TABLE 3

Relationship Between Location of Fluorescent Tracer Deposits and Lymphatic Drainage

\begin{tabular}{|c|c|c|c|c|c|c|c|c|}
\hline \multirow{2}{*}{$\begin{array}{l}\text { Patient } \\
\text { no. }\end{array}$} & \multicolumn{2}{|c|}{ FL (\%) } & \multicolumn{2}{|c|}{ Total RA (\%) } & \multirow{2}{*}{$\begin{array}{l}\text { Correlation between } \\
\text { FL and total RA }\end{array}$} & \multicolumn{2}{|c|}{ RA in SN1 (\%) } & \multirow{2}{*}{$\begin{array}{l}\text { Correlation between } \\
\mathrm{FL} \text { and RA in SN1 }\end{array}$} \\
\hline & Left & Right & Left & Right & & Left & Right & \\
\hline 1 & $47 \pm 11$ & $53 \pm 11$ & 71 & 29 & No (inverted) & 55 & 45 & $\begin{array}{l}\text { Yes (larger variance } \\
\text { in } \mathrm{FL})\end{array}$ \\
\hline 2 & $59 \pm 6$ & $41 \pm 6$ & 73 & 27 & Yes (larger difference in RA) & 52 & 48 & Yes \\
\hline 3 & $49 \pm 7$ & $54 \pm 4$ & 79 & 21 & No (inverted) & 71 & 29 & No (inverted) \\
\hline 4 & $46 \pm 13$ & $54 \pm 13$ & 58 & 42 & Yes (larger difference in FL) & 35 & 65 & $\begin{array}{l}\text { Yes (larger difference } \\
\text { in RA) }\end{array}$ \\
\hline 5 & $39 \pm 7$ & $61 \pm 7$ & 37 & 63 & Yes & 37 & 63 & Yes \\
\hline 6 & $38 \pm 6$ & $69 \pm 9$ & - & - & (No drainage) & - & - & (No drainage) \\
\hline 7 & $68 \pm 8$ & $32 \pm 8$ & 37 & 63 & No (inverted) & 60 & 40 & Yes \\
\hline 8 & $56 \pm 9$ & $44 \pm 9$ & 71 & 29 & Yes (larger difference in RA) & 58 & 42 & Yes \\
\hline 9 & $55 \pm 21$ & $48 \pm 24$ & 54 & 46 & Yes & 58 & 42 & Yes \\
\hline 10 & $45 \pm 4$ & $55 \pm 4$ & 71 & 29 & No & 66 & 34 & \\
\hline 11 & $65 \pm 4$ & $35 \pm 4$ & 39 & 61 & No (inverted) & 26 & 74 & No (inverted) \\
\hline 12 & $38 \pm 0$ & $66 \pm 0$ & 71 & 29 & No (inverted) & 73 & 27 & No (inverted) \\
\hline 13 & $57 \pm 13$ & $43 \pm 13$ & 31 & 69 & $\begin{array}{l}\text { No (inverted and larger } \\
\text { difference in } R A \text { ) }\end{array}$ & 37 & 63 & No \\
\hline 14 & $57 \pm 18$ & $43 \pm 18$ & 86 & 14 & $\begin{array}{l}\text { No (no difference in FL, } \\
\text { clear difference in RA) }\end{array}$ & 100 & - & Yes \\
\hline 15 & $38 \pm 12$ & $61 \pm 12$ & 48 & 52 & Yes & - & - & Yes* $^{*}$ \\
\hline 16 & $68 \pm 4$ & $32 \pm 4$ & 77 & 23 & Yes & 82 & 18 & $\begin{array}{l}\text { Yes (larger difference } \\
\text { in RA) }\end{array}$ \\
\hline 17 & $84 \pm 3$ & $16 \pm 3$ & 73 & 27 & Yes & 100 & - & Yes \\
\hline 18 & $70 \pm 11$ & $30 \pm 11$ & 71 & 29 & Yes & 60 & 40 & Yes \\
\hline 19 & $20 \pm 5$ & $87 \pm 16$ & 27 & 73 & Yes & - & 100 & Yes \\
\hline
\end{tabular}

${ }^{*} \mathrm{SN}$ visualized with SPECT/CT instead of lymphoscintigraphy.

$\mathrm{RA}=$ radioactivity.

In each patient, fluorescence within different sections of prostate was determined and mean percentage of fluorescence (\%FL) was calculated on both sides of body (L/R). To evaluate relationship between presence of fluorescence and radioactivity, percentages on $L$ and $\mathrm{R}$ were compared. When highest percentage of $F L$ and RA was measured on one side of body ( $L$ or $R)$, this was noted as positive correlation. 
zone of all sections of the prostate, the number of visualized LNs increased to an average of 4.7 per patient (patients 3,5 , 7, 9, 10, 12, and 14). Apparently, the drainage is reduced when the injection is placed partly or completely in the central zone.

A difference in drainage was also observed after injection in different sections of the prostate (Fig. 1, z-axis). When tracer deposits were unevenly distributed between the different sections, no positive correlation between the site of the fluorescent deposit and the radioactivity in the LNs was found (Table 3). Placement of tracer deposits in the peripheral zone near the base or apex resulted in visualization of, on average, $3.5 \mathrm{LNs}$ per patient (patients 1, 7, 11 , and 14). When tracer deposits were placed in the peripheral zone in the mid gland of the prostate, the number of visualized LNs per patient increased to an average of 6 (patients 2, 4, 8, and 9).

In addition to the number of visualized LNs, a clear correlation between the distribution of the tracer deposits (Table 1) and the location of the visualized SN (Table 2) was observed. Injection into the peripheral zone near the base of the prostate resulted in visualization of a SN in the common iliac area (patients 7, 14, and 17), whereas in 1 patient the injection was localized near the apex of the prostate, yielding a paracaval SN (patient 9).

\section{DISCUSSION}

Although we evaluated a relatively small patient group, the results obtained in this study underline the value of the hybrid surgical guidance technology. The study showed that the position at which a tracer deposit is placed in the prostate influences the lymphatic drainage pattern and that large variations in placement do occur in practice. The first point is underlined by Wawroschek et al., who showed that in canines, the site of injection influences the drainage pattern from the prostate (16).

Overall, our data suggest that drainage seems to be higher from the peripheral zone than from the central zone; injection into the peripheral zone of the prostate resulted in visualization of more LNs per patient (Tables 2 and 3). This is in line with the hypothesis stated by Brössner et al. (11) that different zones of the prostate follow different lymphatic drainage patterns. Possibly this difference in lymphatic drainage can be explained by the more densely packed structure of the peripheral zone (11). As such, injection of the radiotracer may result in a local increase in interstitial fluid pressure, leading to an increase in lymphatic drainage. The relationship between increased fluid pressure after injection and lymphatic drainage may also explain why deposits on only the left or right side of the prostate result in a greater number of visualized SNs and LNs or a higher radioactive counting rate in SN1 (Table 2).

Placement of deposits in different regions (along the $z$-axis; Fig. 1) of the prostate also resulted in visualization of LNs in different basins (Table 2). Deposits clearly situated near the base of the prostate seemed to lead to visualization of LNs in the common iliac region, whereas deposits near the apex of the prostate resulted in visualization of a paracaval LN. In all cases, drainage tended to occur via the standard lymphatic drainage route of the prostate, including the obturator, internal iliac, external iliac, common iliac, and presacral nodes (17), which are also the most frequent sites of lymphatic metastatic spread (18).

Ideally, tumor-draining LNs are identified, as these nodes are most likely to harbor possible metastases. Unfortunately, actual visualization of prostate tumor tissue in vivo is difficult using current standard imaging methods. Considering that prostate cancer develops predominantly in the peripheral zone $(9,10)$, which is in line with the results shown in Supplemental Table 2, we suggest that distribution of tracer over the peripheral zone (Q3 and Q4) yields the highest chance of visualizing the tumor-draining LNs. To compensate for injection errors resulting in less drainage to one side, such as through loss of tracer to the bladder, we recommend that whenever preoperative imaging detects only a unilateral $\mathrm{SN}$, contralateral retroperitoneal $\mathrm{LN}$ dissection should be performed.

In the current setting, tracer was deposited into the prostate under ultrasound guidance, which has a poor sensitivity for tumor visualization. The zonal anatomy of the prostate can be visualized using T2-weighted MR images $(19,20)$. Therefore, fusion of MR images with real-time transrectal ultrasound may provide a solution for more accurate injection procedures without resulting in major adaptations to current patient logistics. Also, because MRI-guided biopsies (21) and MRI-guided focal therapy (22) allow real-time visualization of needle placement, methods for MRI-guided tracer injections could be explored.

The recently developed hybrid radiocolloid allowed us to accurately document tracer locations in archived prostate material. These findings may have implications for $\mathrm{SN}$ biopsies in prostate cancer patients, but more extensive research and study are necessary before conclusions can be drawn.

\section{CONCLUSION}

Besides the potential to improve surgical guidance during (robot-assisted) SN biopsy, hybrid ICG- ${ }^{99 m} \mathrm{Tc}-$ nanocolloid provides a unique tool to postoperatively monitor the location of tracer deposits in the prostates of individual patients. This study suggests that the location of intraprostatic tracer deposition may influence preoperatively visualized lymphatic drainage patterns and, as such, the $\mathrm{SN}$ procedure as a whole in prostate cancer patients.

\section{DISCLOSURE STATEMENT}

The costs of publication of this article were defrayed in part by the payment of page charges. Therefore, and solely to indicate this fact, this article is hereby marked "advertisement" in accordance with 18 USC section 1734. 


\section{ACKNOWLEDGMENT}

This research was supported, in part, by a KWF translational research award (grant PGF 2009-4344), a NOW VIDI grant (STW BGT 11271), and by the Nijbakker Morra stichting. Karl Storz endoscopes supported this research with a D-light system. We thank the urologists, operation department practitioners, and technicians of the nuclear medicine department for their contribution. No other potential conflict of interest relevant to this article was reported.

\section{REFERENCES}

1. Weckermann D, Dorn R, Trefz M, Wagner T, Wawroschek F, Harzmann R. Sentinel lymph node dissection for prostate cancer: experience with more than 1,000 patients. J Urol. 2007;177:916-920.

2. Briganti A, Karnes RJ, Pozzo LFD, et al. Combination of adjuvant hormonal and radiation therapy significantly prolongs survival of patients with pT2-4 pN+ prostate cancer: results of a matched analysis. Eur Urol. 2011;59:832-840.

3. Jeschke S, Beri A, Grüll M, et al. Laparoscopic radioisotope-guided sentinel lymph node dissection in staging of prostate cancer. Eur Urol. 2008;53:126-132.

4. Meinhardt W, Olos RAV, van der Poel HG, Bex A, Horenblas S. Laparoscopic sentinel node dissection for prostate carcinoma: technical and anatomical observations. BJU Int. 2008;102:714-717.

5. Valsecchi ME, Silbermins D, de Rosa N, Wong SL, Lyman GH. Lymphatic mapping and sentinel lymph node biopsy in patients with melanoma: a meta analysis. J Clin Oncol. 2011;29:1479-1487.

6. Giuliano AE, Kirgan DM, Guenther JM, Morton DL. Lymphatic mapping and sentinel lymphadenectomy for breast cancer. Ann Surg. 1994;220:391-398.

7. Morton DL, Wen DR, Wong JH, et al. Technical details of intraoperative lymphatic mapping for early stage melanoma. Arch Surg. 1992;127:392-399.

8. Meinhardt W. Sentinel node evaluation in prostate cancer. EAU-EBU Update Ser. 2007;5:223-231
9. Holl G, Dorn R, Wengenmair H, Weckermann D, Sciuk J. Validation of sentinel lymph node dissection in prostate cancer: experience in more than 2,000 patients. Eur J Nucl Med Mol Imaging. 2009;36:1377-1382.

10. Coakley FV, Hrivak H. Radiologic anatomy of the prostate gland: a clinical approach. Radiol Clin North Am. 2000;38:15-30.

11. Brössner C, Ringhofer H, Hernady T, Kuber W, Madersbacher S, Pycha A. Lymphatic drainage of prostatic transition and peripheral zones visualized on a three-dimensional workstation. Urology. 2001;57:389-393.

12. Briganti A, Blute ML, Eastham JH, et al. Pelvic lymph node dissection in prostate cancer. Eur Urol. 2009;55:1251-1265.

13. Buckle T, van Leeuwen AC, Chin PTK, et al. A self-assembled multimodal complex for combined pre- and intra-operative imaging of the sentinel node. Nanotechnology. 2010;21:355101.

14. van Leeuwen AC, Buckle T, Bendle G, et al. Tracer cocktail injections for combined pre-and intraoperative multimodal imaging of lymph nodes in a spontaneous mouse prostate model. J Biomed Opt. 2011;16:016004.

15. van der Poel HG, Buckle T, Brouwer OR, Valdés Olmos RA, van Leeuwen FWB. Intraoperative laparoscopic fluorescence guidance to the sentinel lymph node in prostate cancer patients: clinical proof of concept of an integrated functional imaging approach using a multimodal tracer. Eur Urol. 2011;60:826833.

16. Wawroschek F, Wengenmair H, Senekowitsch-Schmidtke R, et al. Prostate lymphoscintigraphy for sentinel lymph node identification in canines: reproducibility, uptake, and biokinetics depending on different injection strategies. Urol Res. 2003; 31:152-158.

17. Park JM, Charnsangavej C, Yoshimitsu K, Herron D, Robinson TJ, Wallace S. Pathways of nodal metastasis from pelvic tumors. Radiographics. 1994;14:13091321.

18. Yu KK, Hawkins RA. The prostate: diagnostic evaluation of metastatic disease. Radiol Clin North Am. 2000;38:139-157.

19. Mazaheri Y, Shukla-Dave A, Muellner A, Hricak H. MRI of the prostate: clinical relevance and emerging applications. J Magn Reson Imaging. 2011;33:258-274.

20. Verma S, Rajesh A. A clinically relevant approach to imaging prostate cancer. AJR. 2011;196(suppl):S1-S10.

21. Haker SJ, Mulkern RV, Roebuck JR, et al. Magnetic resonance-guided prostate interventions. Top Magn Reson Imaging. 2005;16:355-368.

22. Lindner U, Lawrentschuk N, Trachtenberg J. Image guidance for focal therapy of prostate cancer. World J Urol. 2010;28:727-734. 